\title{
جريمة إجهاض الحامل لتفسها في التشريع الجزائري
}

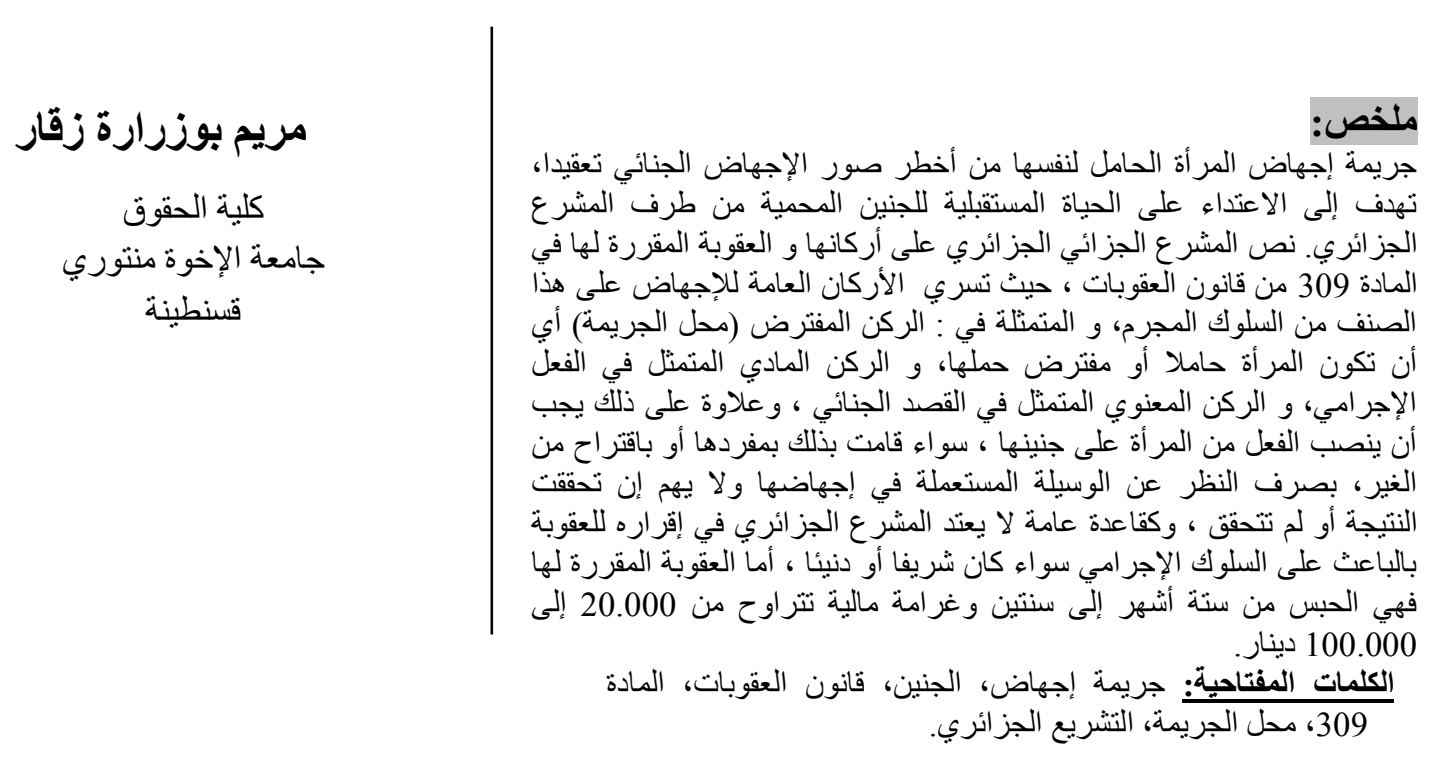

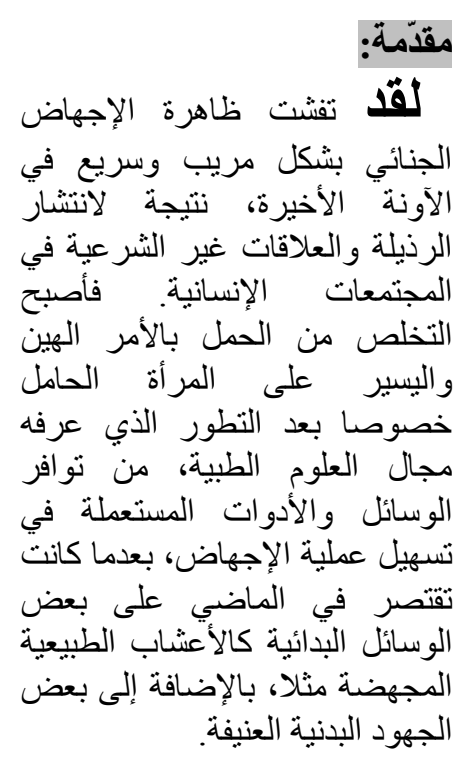

\begin{abstract}
:
The fact of abortion woman is one of the most dangerous complex penal act.

It is a violation against future life of foetus, which is protected by the Algerian legislation. This later established its rules and defined its sentences according to the article 309 of the penal code. The general rules of abortion are enforced in the type of crime behaviour: eventual element (crime object) in the case of a pregnant woman or probably pregnant. The materialelement, which is the criminal act. The moral element is the criminal intention. The woman who practice lonely, assisted or proposed by another person out of spite the mean used in the abortion, despite the success or the failure of the abortion process. General rule: The Algerian legislation do not take in consideration in passing sentence the underlying reason of the criminal act. The sentence of abortion is six months until two years in prison and 20.000 until 100.000 Algerian dinars fine.
\end{abstract}




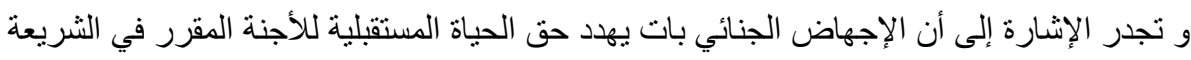

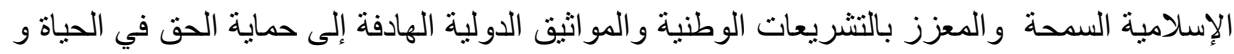

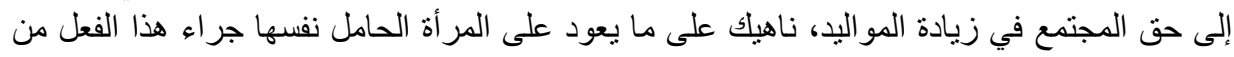

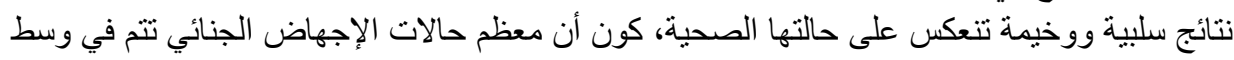

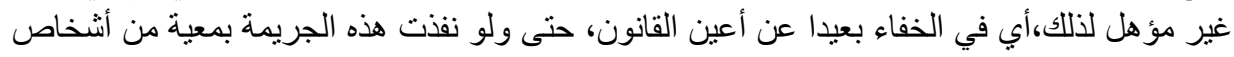

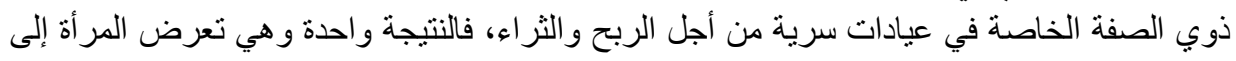

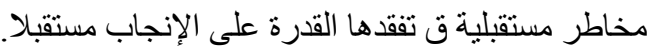

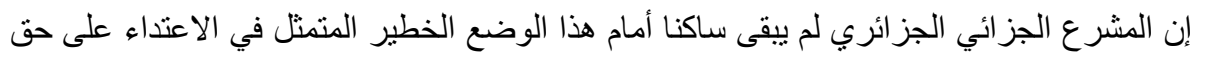

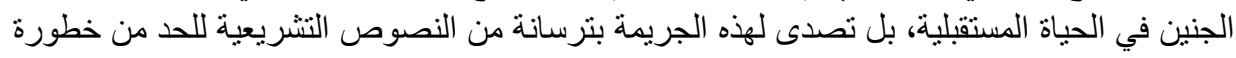

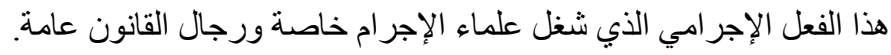

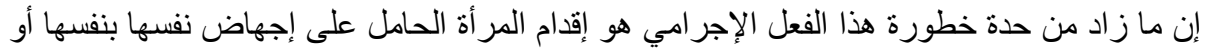

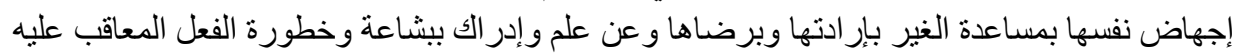

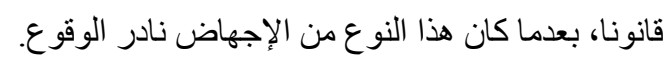

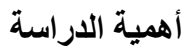

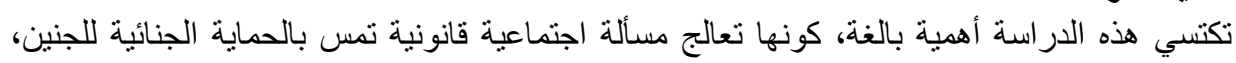

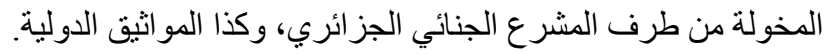

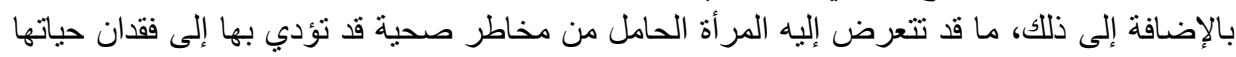
جر اء هذا الإجهاض الجنائي.

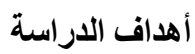

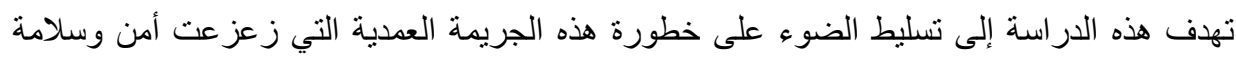

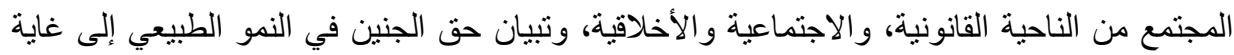

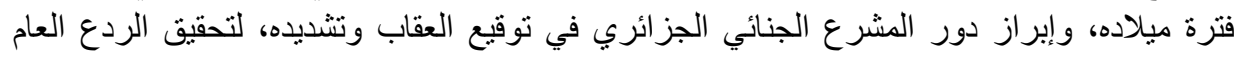

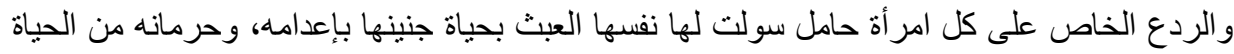
المستقلية مهما كان الباعث على ذلك سواء لأسباب اقتصادية، اجتماعية، صحية أو أخلاقية.

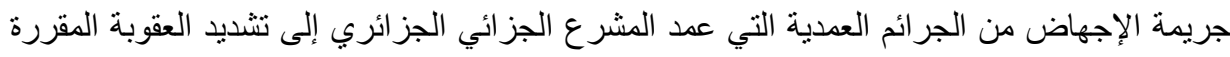

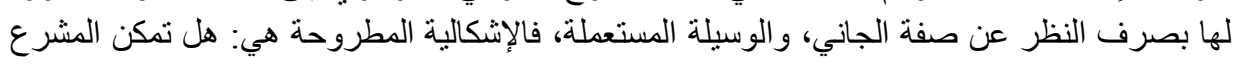

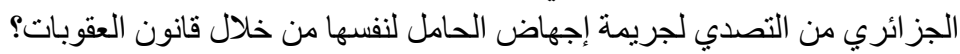

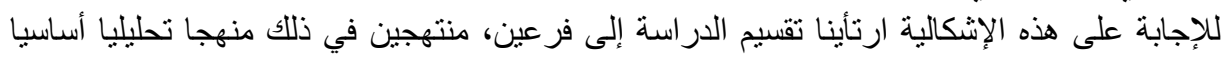

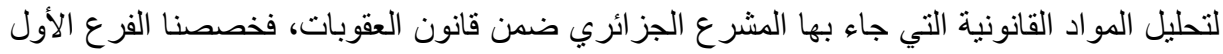

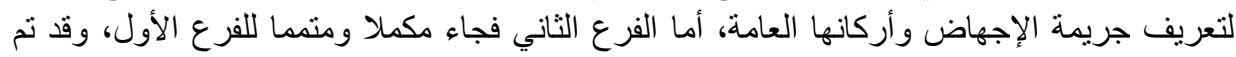

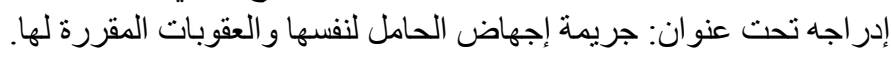
الفرع الأول: تعريف جريمة الإجهاض وأن أركانها

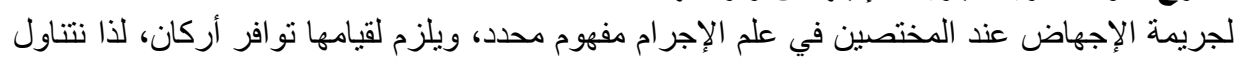
في هذا الفرع تعريف الإجهاض أو لا ثم أركانه ثنانيا. 
أولا : تعريف الإجهاض

لم يورد المشرع الجزائي الجزائري في قانون العقوبات تعريف للإجهاض شأنه في ذلك شأن

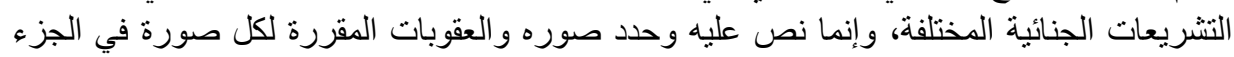

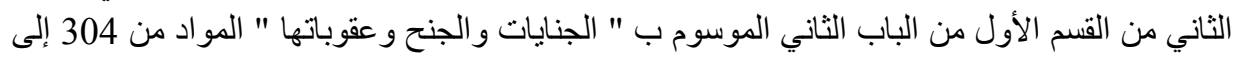

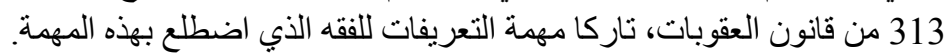
و قد عرفت الدكتورة فوزية عبد الستار الإجهاض بأنه: " إنهاء حالة الحمل قصدا قبات فبل مو عد الو لادة

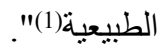
وعرفه الأستاذ رؤوف عبيد بأنه: " استعمال وسيلة صناعية تؤدي إلى طرد الجنين قبل موعد الو لادة، إذا تم بقصد إحداث هذه النتيجة(2)".

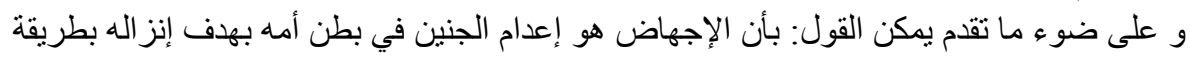
عمدية قبل مو عد الوضع الطبيعي.

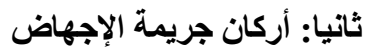

الإجهاض اعتداء يقع أصلا على حق الجنين الجنين في الحياة المستقبلية، هذا الحق يقتضي تمكين الجنين من

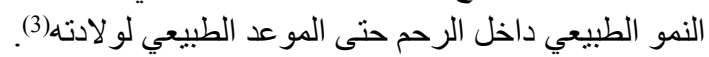

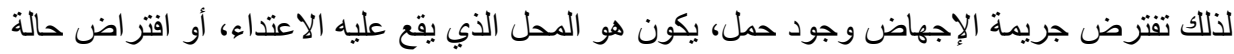

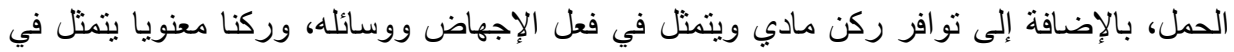
القصد الجنائي و هو ما سنتناوله تباعا فئما فيما يأني.

1 - الركن المفترض (محل الجريمة)

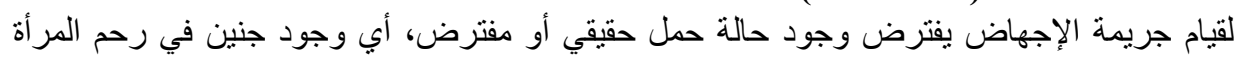

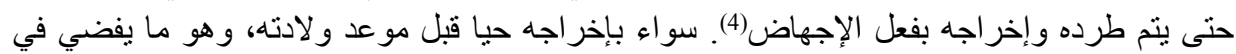
الغالب إلى وفاته، أو بقتله في الرحم(5).

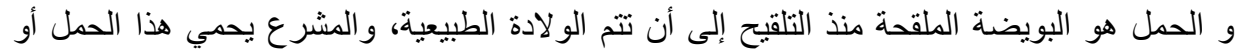

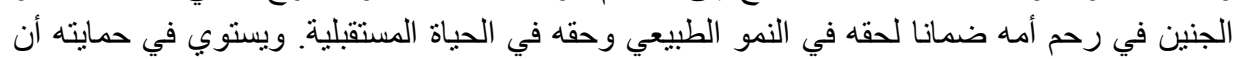

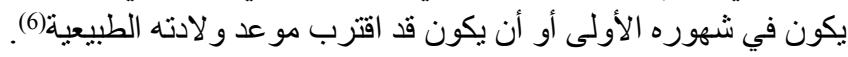

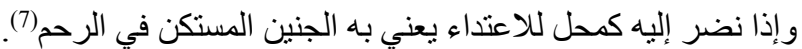

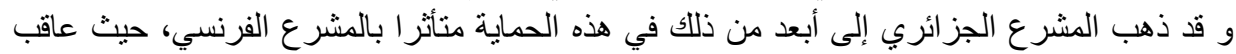

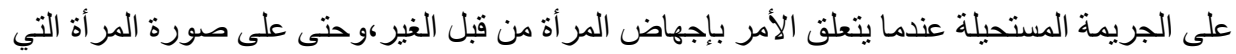

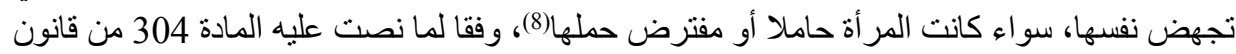

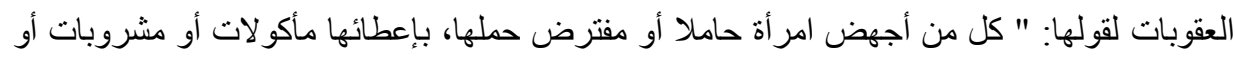

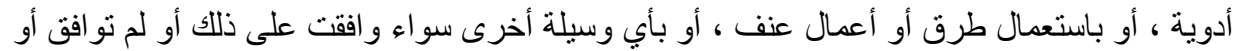

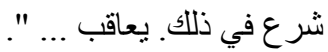
نستخلص من ذللك أن المشرع الجزائري كان صارما فأ في الأحكام الخاصة بجريمة الإجهاض، من خلال

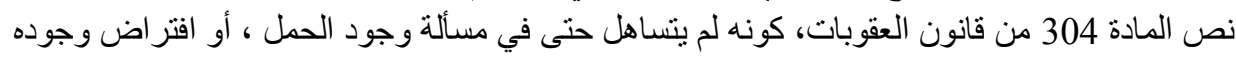

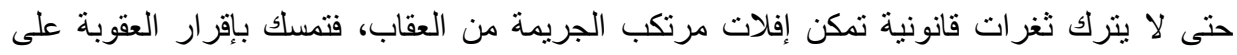

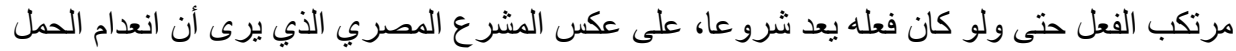

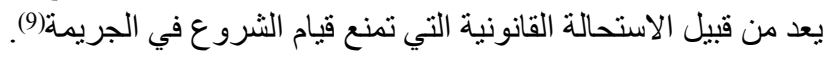




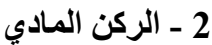

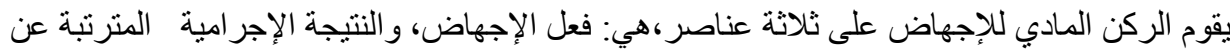
فعل الإجهاض، المتمنلة في موت الجنين أو خروجه قبل حلول مو عد الوضع الطبيعي،و العلاقة السبيبية

بينهما.

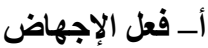

يتحقق الإجهاض بكل فعل يكون من شأنه إخراج الجنين من الرحم قبل الموعد الطبيعي

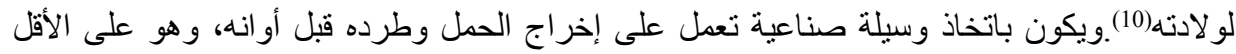

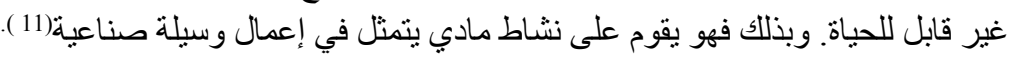

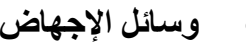

لقد جاءت وسائل الإجهاض في نص المادة 304 من قانون العقوبات على سبيل المثال لا على سبيل

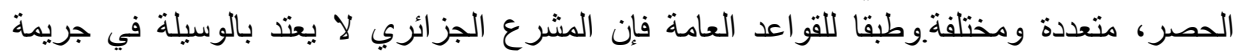

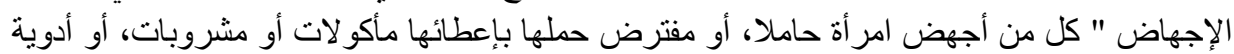

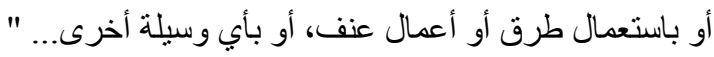

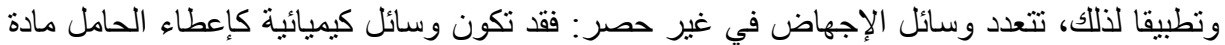

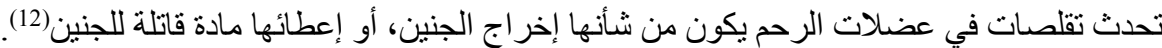

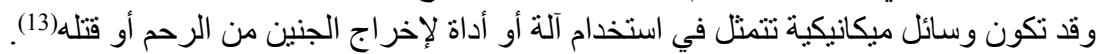

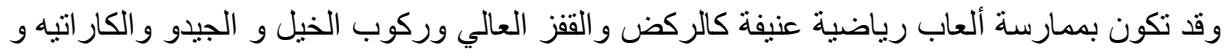

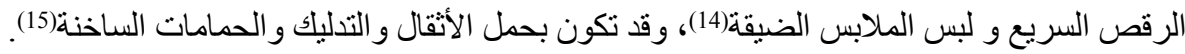

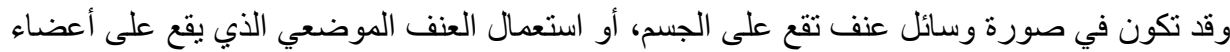

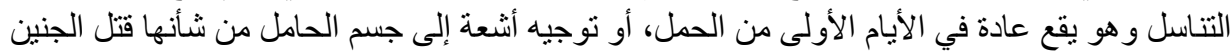

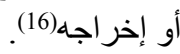
وقد تكون وسائل طبية بيتخدمها الأطباء من أجل إجهاض الجنين كالحقن المضادة لمادة

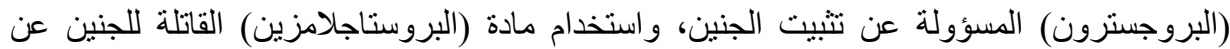

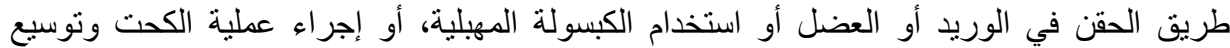

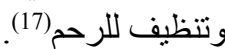

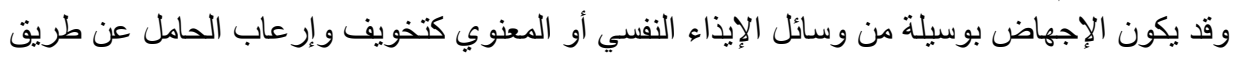
الأصوات المر عبة وارتداء الأقتعة كالأشباح و الحيو الانات المفترسة وحرمان الحامل من النوم ليلا و القلق

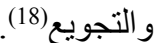
ومهما كانت الوسيلة، يجب إقامة الدليل على أن الوسيلة المستعملة كانت السبب في الإسقاط، و الفصل في

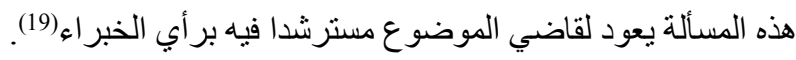

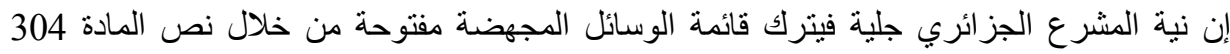

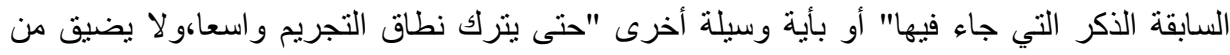

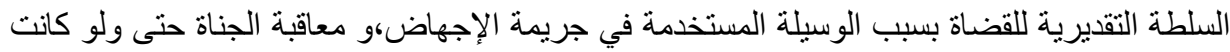

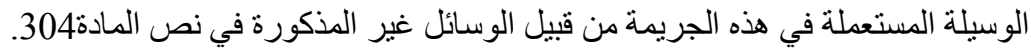


ب-النتيجة الإجرامية

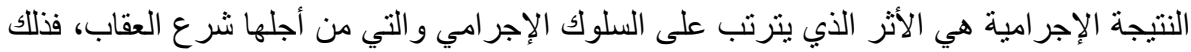

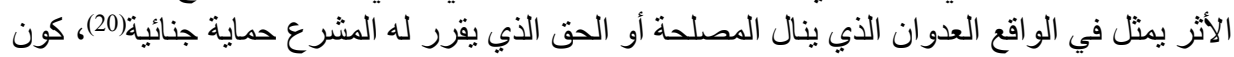

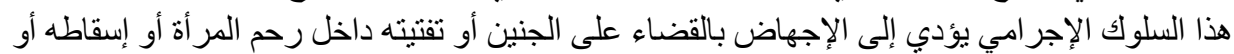

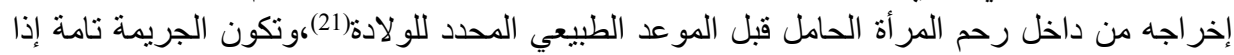

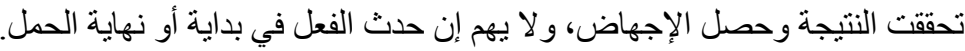

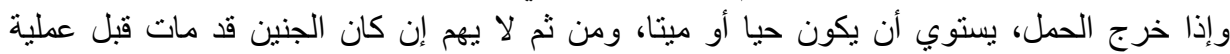

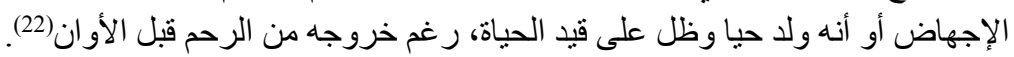

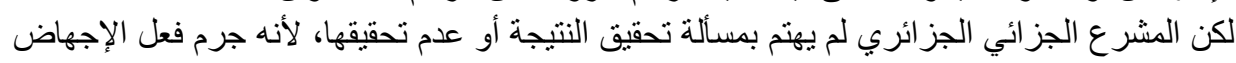

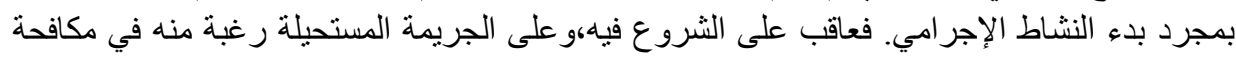

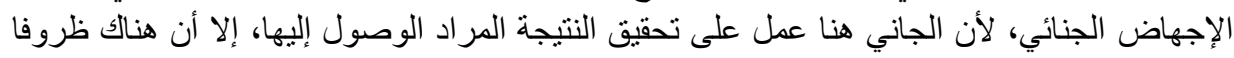

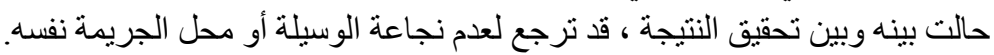

ج-علاقة السببية بين الفعل والنتيجة

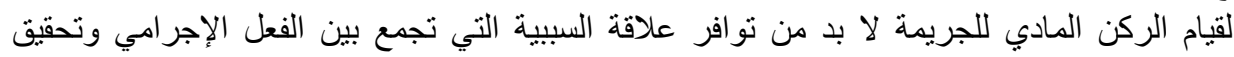

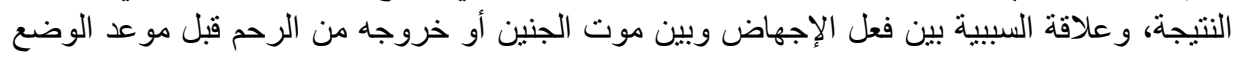
الطبيعي.

فالإنسان لا يسأل عن النتيجة إلا إذا كانت ناجمة عن سلوكه، والفاعل لا يسأل عن جريمة الإجهاض إلا

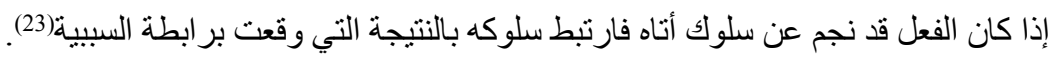

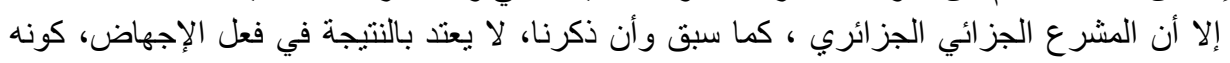

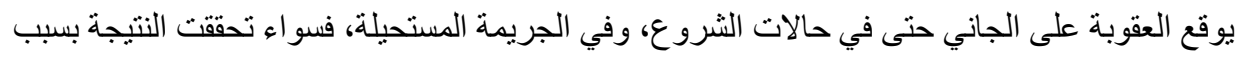

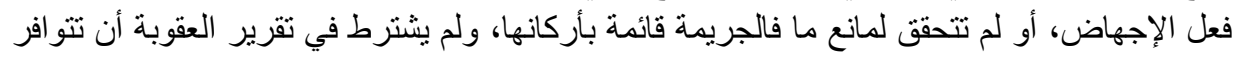

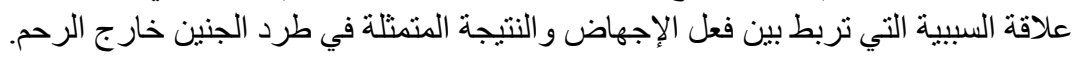

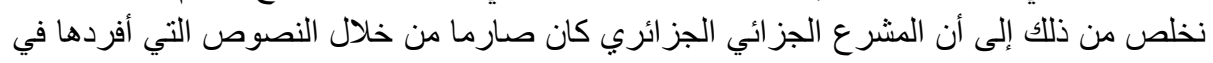

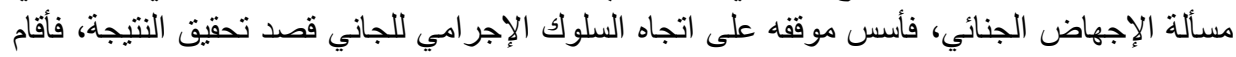

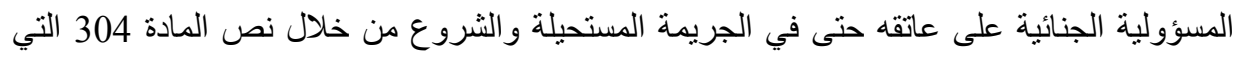

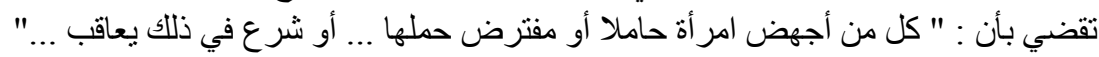

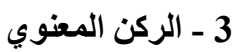

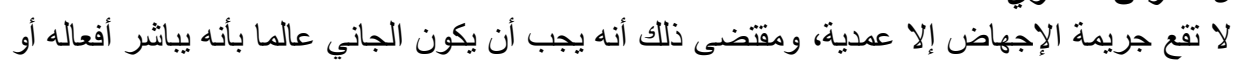

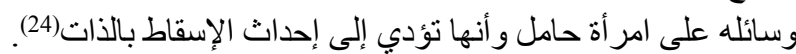

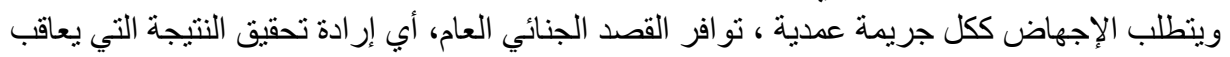

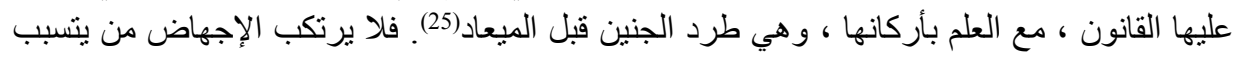

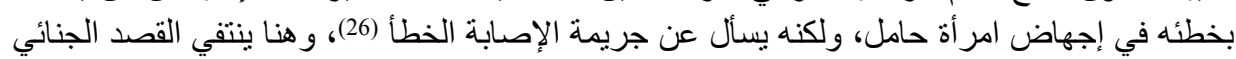

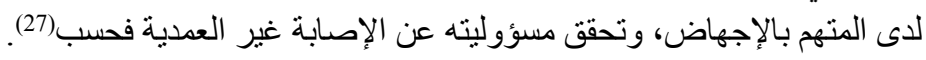

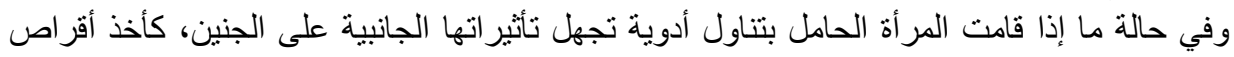

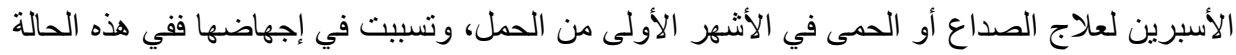

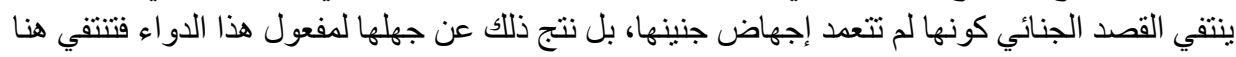

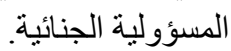


وطبقا للقو اعد العامة لا أثر للباعث على القصد الجنائي، فيتساوى الدافع مهما كان هدفه، ثم أنه لا أثر

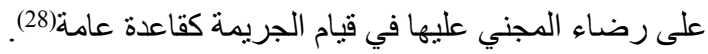

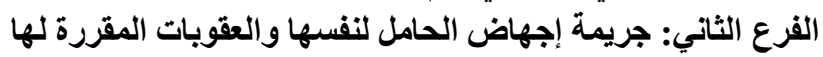

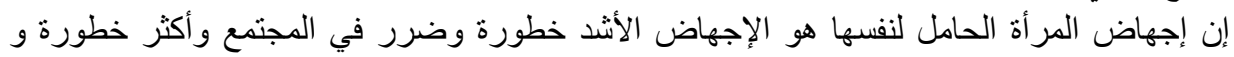

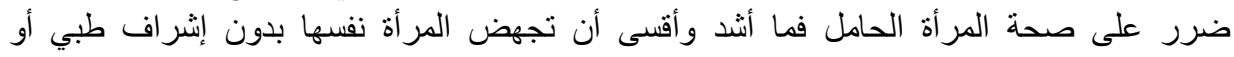
رعاية(29)

ولدراسة هذا النوع من الإجهاض الجنائي ارتأينا تقسيم هذا الفرع إلى أولا : صور إجهاض الحامل

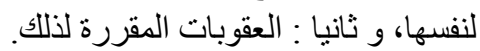

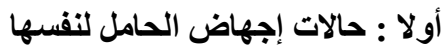

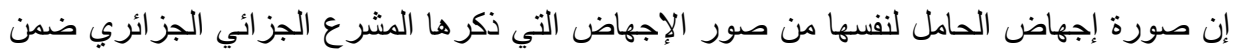

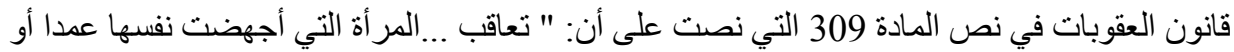

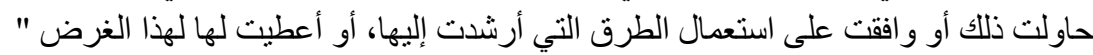

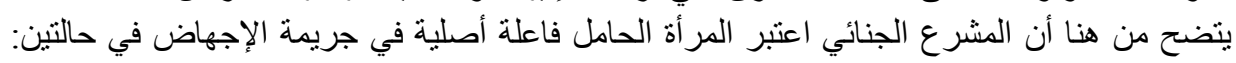

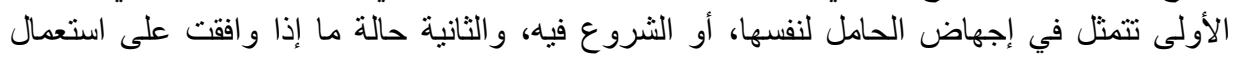

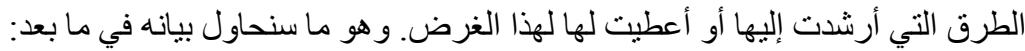

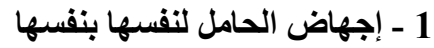

إن إجهاض المر أة لنفسها لله مفهوم محدد، تقوم فيه جريمة الإجهاض بنوفر ركنيها المادي و المعنوي ،

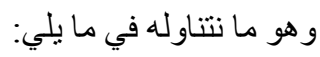

أ_المقصود بإجهاض الحامل لنفسها بنفسيها

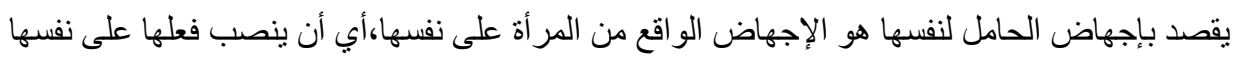

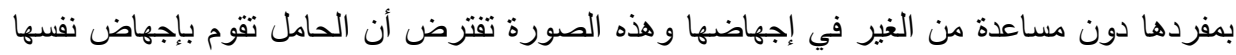

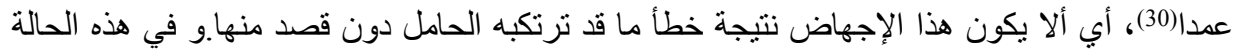

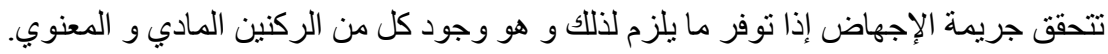

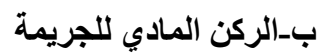

تقوم جريمة إجهاض الحامل لنفسها على الأركان العامة لجريمة الإجهاض السابق توضيحها مع إضافة

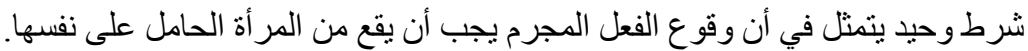

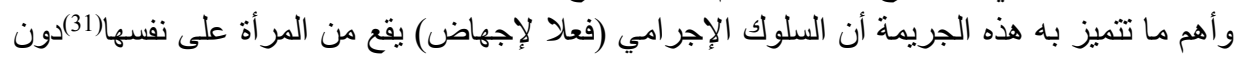

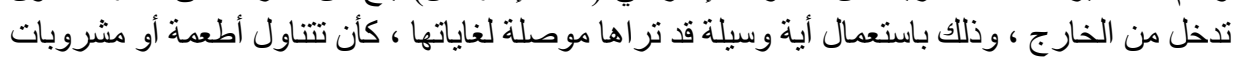

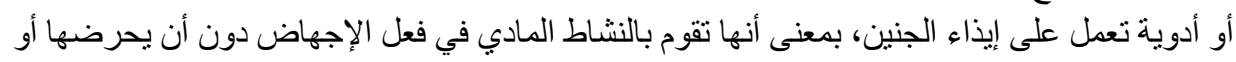

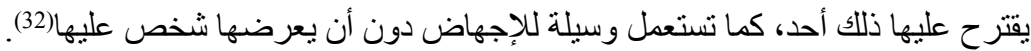

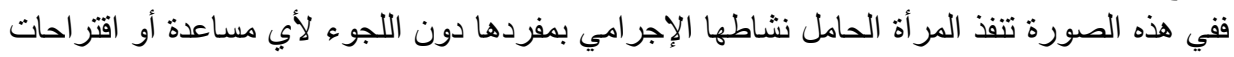

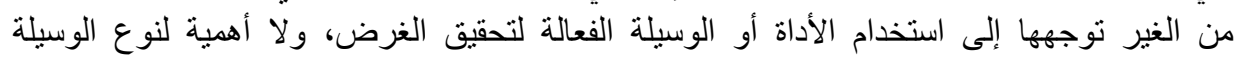

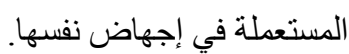
كما أن المشرع الجنائي لا بعتد بالنتيجة ،سو اء تحققت أو لم تتحقق لسبب ما حال دال دون ذلإنك، فيكفي أنها

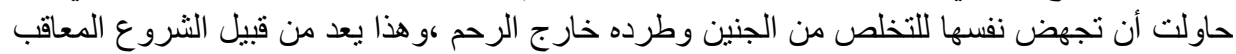

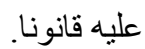




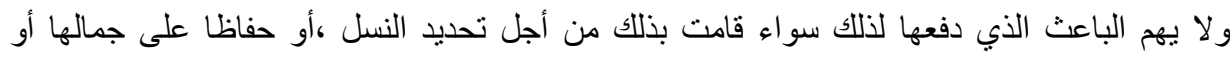

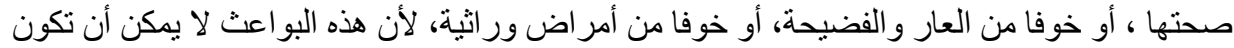

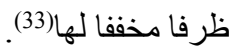
ج-الركن المغنوي

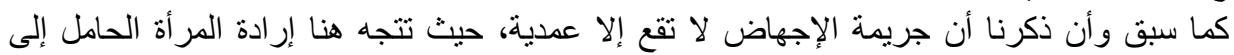

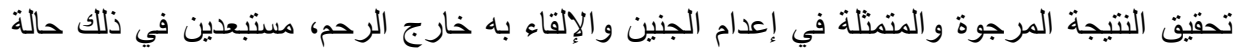

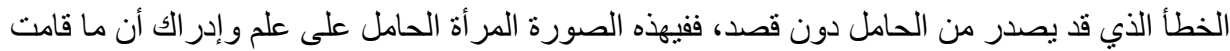

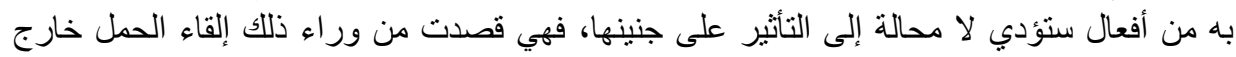

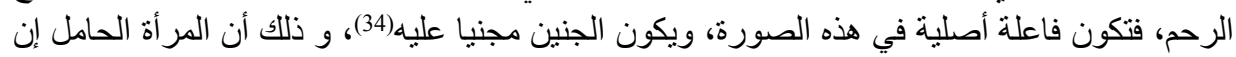

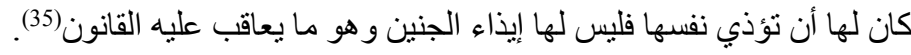

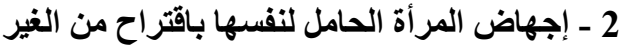

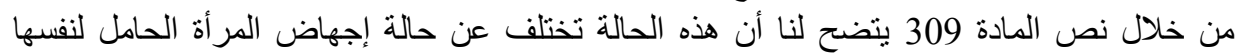

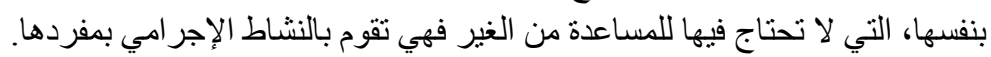

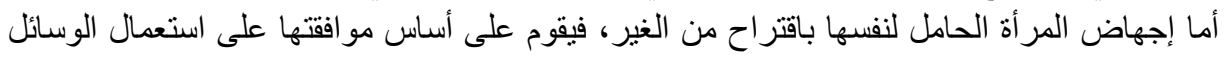

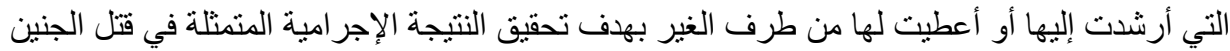

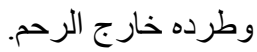

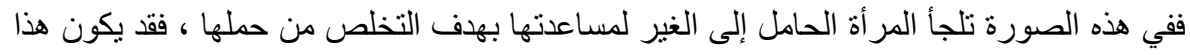

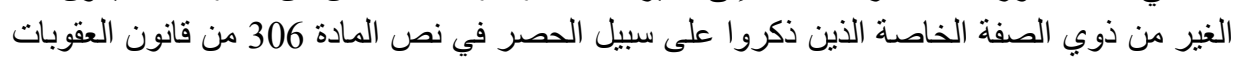

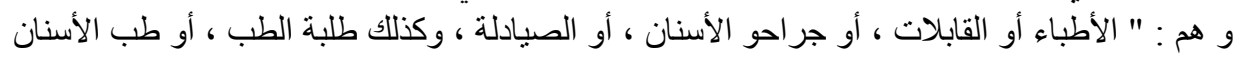

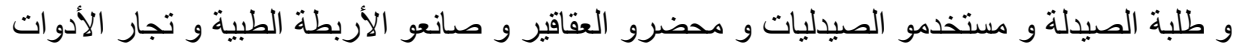

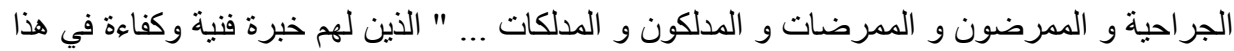

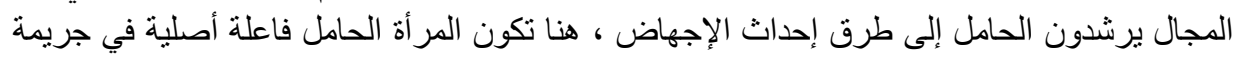

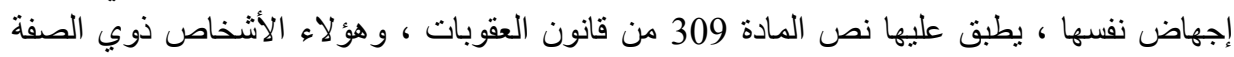

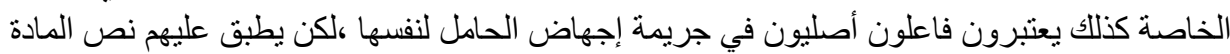
306 من قانون العقوبات. وقد يحصل أن تكون المر أة التي تجهض نفسها طبيبة أو قابلة أو صيدلية أو جراحة أسنان أو طالبة في

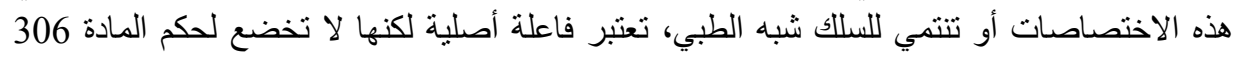

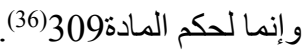

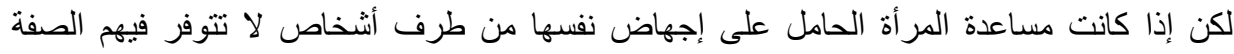

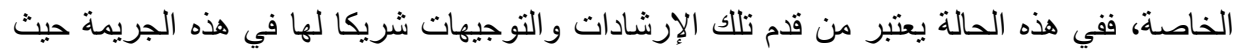

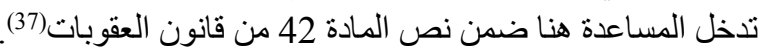

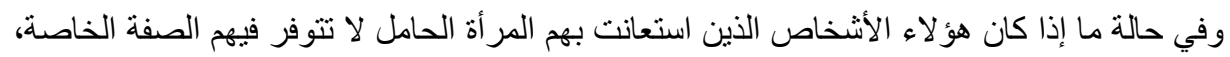

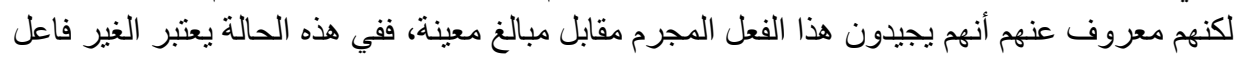

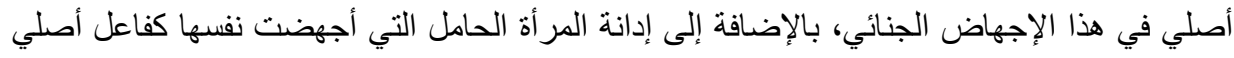

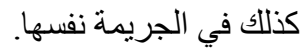




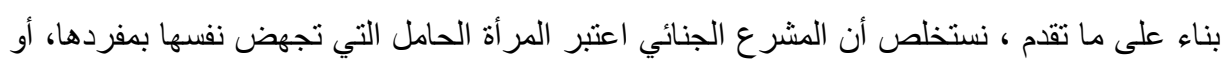

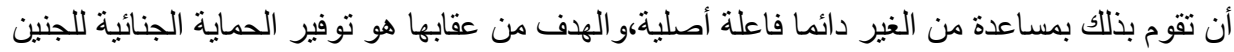

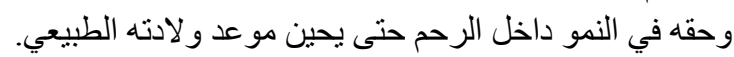

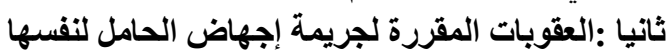

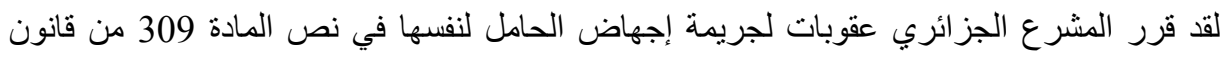

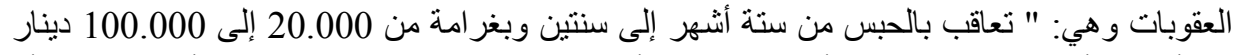

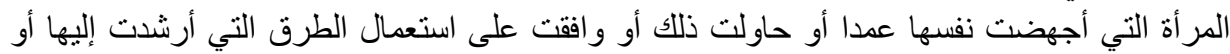

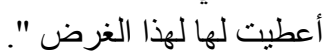

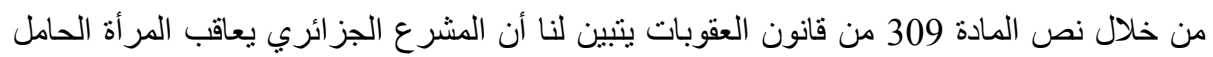

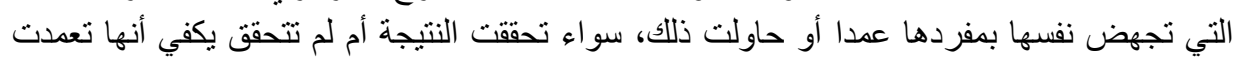
إجهاض الجنين بعقوبة الحبس من ستة أثنهر إلى سنتين بالإضافة إلى غر امة مالى مالية تقدر ما بين 20.000 و100.000 دينار جز ائري كعقوبة أصلية.

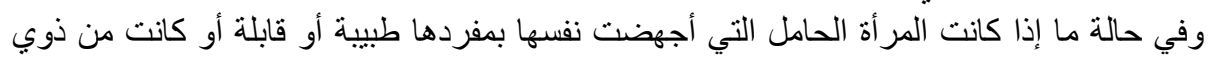

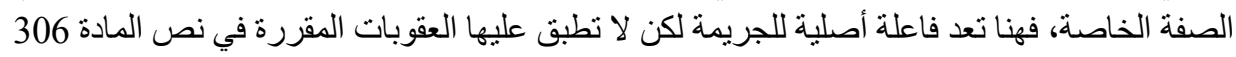

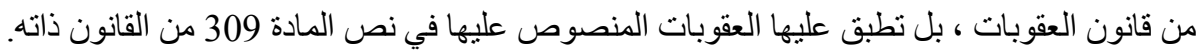

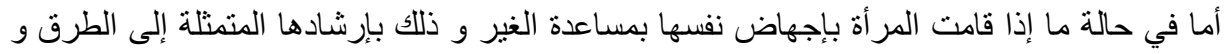

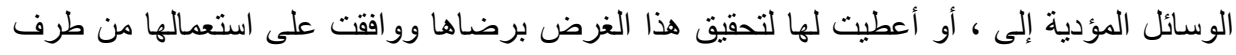

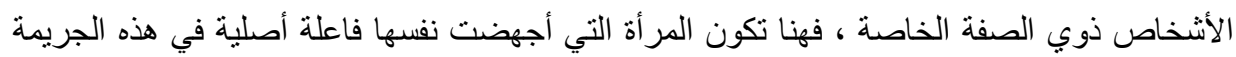

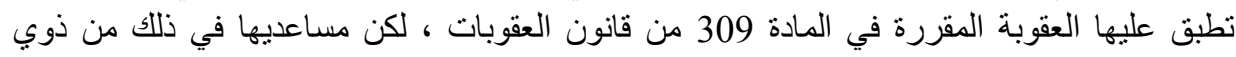

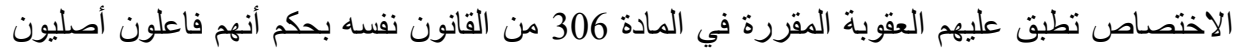

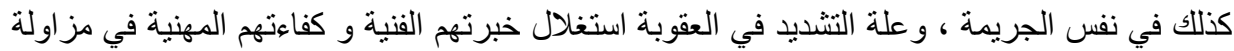

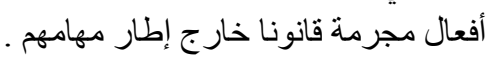

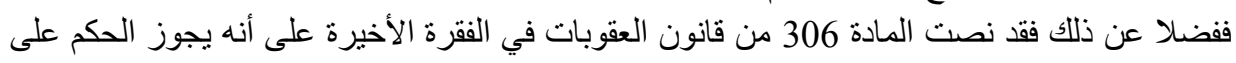

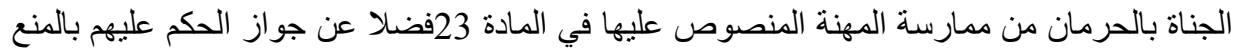

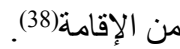

لكن إذا كان هذا الغير لا تتوفر فيه الصفة الخاصة واعتاد على ممارسة الإجهاض الجنائي بتقيم وسائل

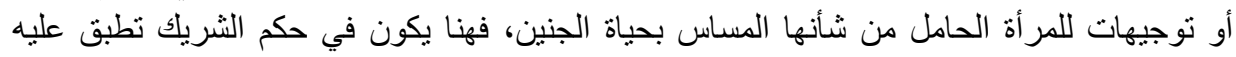

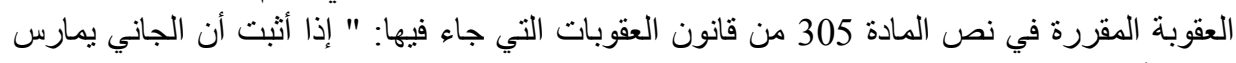

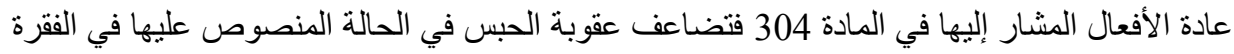
الأولى وترفع عقوبة السجن المؤقت إلى الحد الأقصى ". 


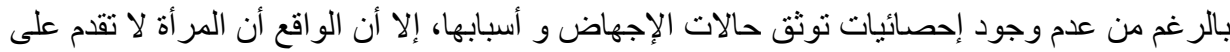

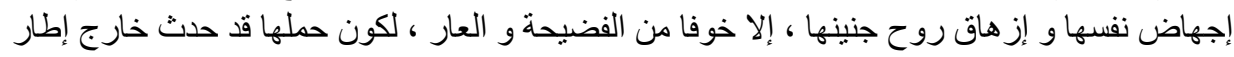

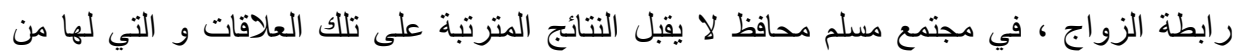

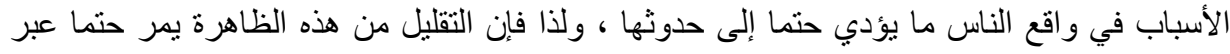

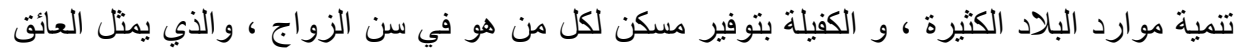

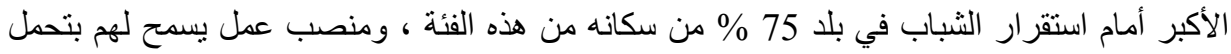

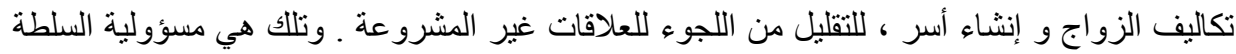
العامة في البلاد.

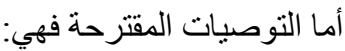
1 - يجب توعية النساء الحوامل من أخطار هذا الفعل المجرم على صحتهم على مستوى دور العيادات

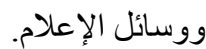

2-تقوية الوازع الديني لاى الفتيات والفتيان، وضرورة التمسك بالقيم والعادات في المجتمعات الإسلامية.

3 - على المشرع الجز ائري تثديد العقوبة على المر أة التي أجهضت حملها بنفسهاورفع قيم الغرامات المقررة لها.

4 - يجب على المشر ع الجز ائري فرض رقابة مستمرة على عيادات التوليد الخاصة لمكافحة الإجهاض

5 الجنائي. على المثر ع الجز ائري تكثيف الرقابة على الصيدليات للمنع تسريب الأدوية المجهضية.

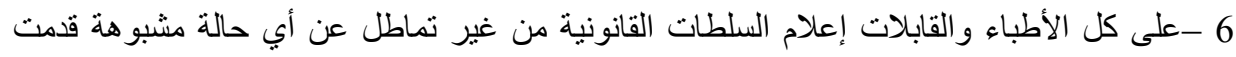
إليهم توحي بأنها إجهاض جنائي لتحقيق الردع العام و الردع الخاص.

1- فوزية عبد الستار، شرح قانون العقوبات القسم الخاص، دار النهضة العربية،القاهرة،1982،

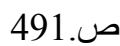
2- رؤوف عبيد، جرائم الاعتداء على الأشخاص والأموال،الطبعة الثامنة،دار الفكر العربي،1985،

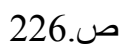

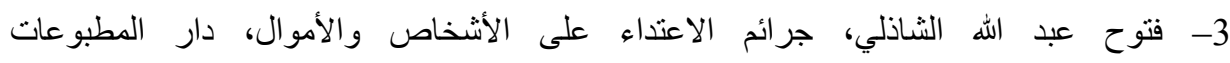

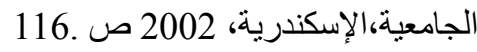
4- عبد المهيمن بكر، جر ائم الاعتداء على الأشخاص و الأمو ال، القسم الخاص في قانون العقوبات، دار

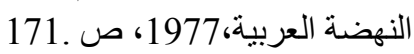

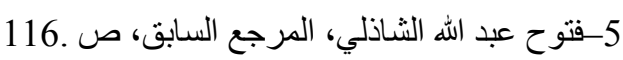

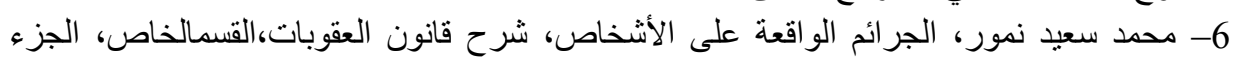

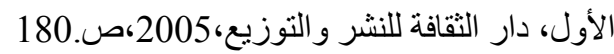
7- محمود نجيب حسني،شرح قانون العقوبات، القسم الخاص، الطبعة الرابعة، دار النهضة

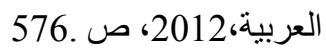


8- أحسن بوسقبعة،الوجيز في القانون الجز ائي الخاص، الطبعة الرابعة عشر، الجزء الأول، دار هومة

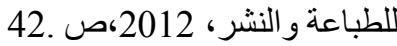

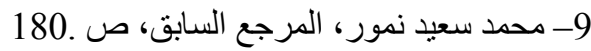

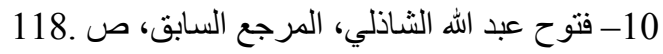

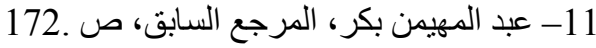

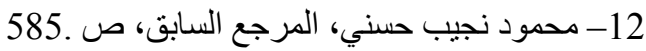

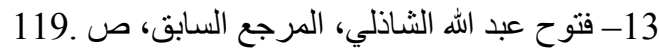

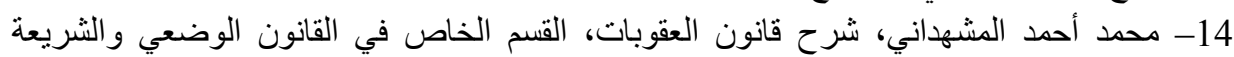

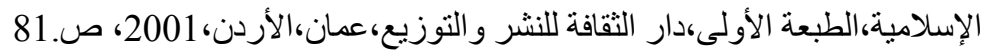

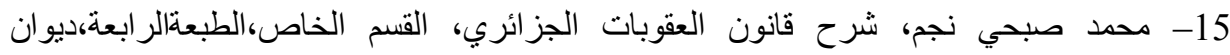

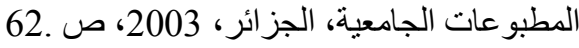
16- حسن الربيع،الإجهاض في نظر المشرية المرع الجنائي،(دراسة مقارنة)، الطبعة الرابعة، دار الثقافة

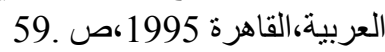

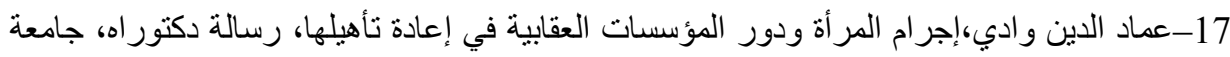

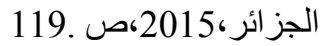

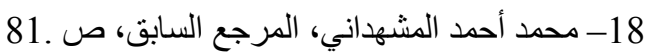

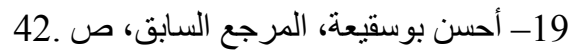

20- 20

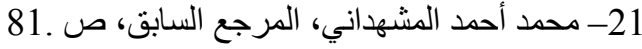

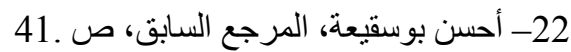

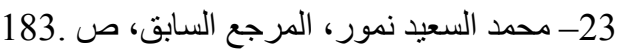

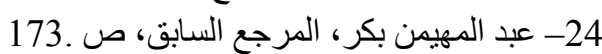

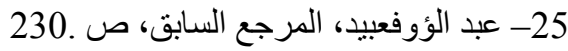

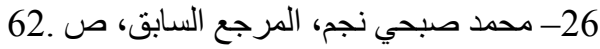

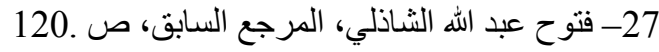

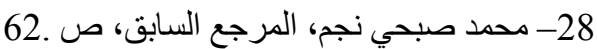

29- عبد الرحيم صدقي،جر ائم الأسرة في الثريعة الإسلامية والقانون المصريو الفرنسي، مكتبة نهضة

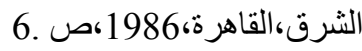

30- منال مروان، الإجهاض في القانون الجنائي، دراسة مقارنة، رسالة لنيل درجة الدكتوراه في

الحقوق، جامعة دمشق،

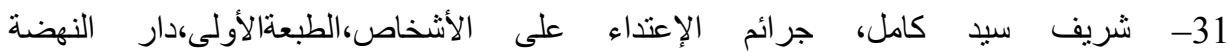

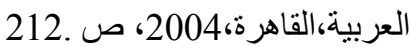

32

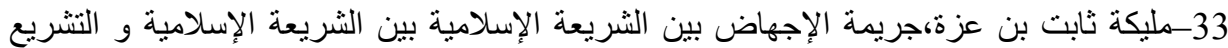

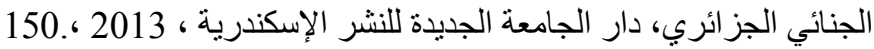

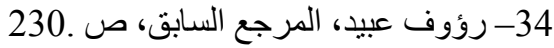

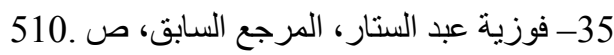




$$
\text { 36- أحسن بوسقيعة، المرجع السابق، ص تص }
$$

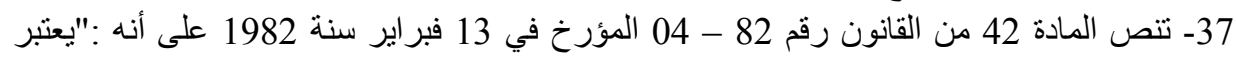

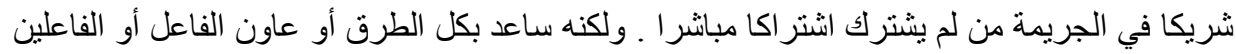

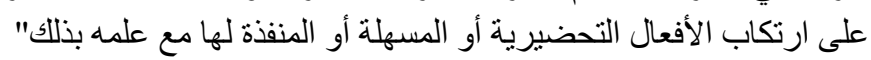

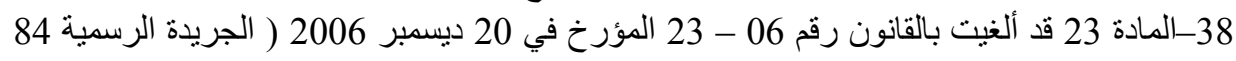

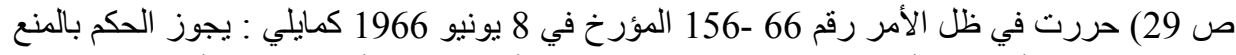

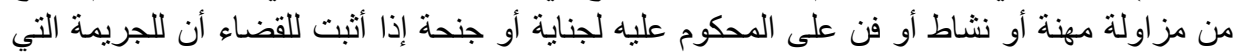

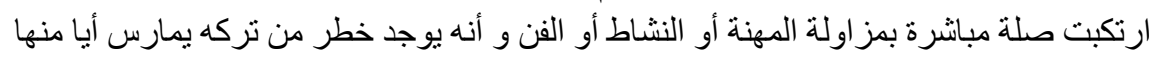

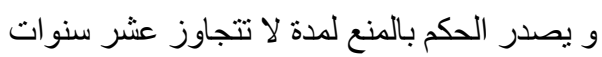
و يجوز أن يؤمر بالنفاذ المعجل بالنسبة لهذا الإجراء

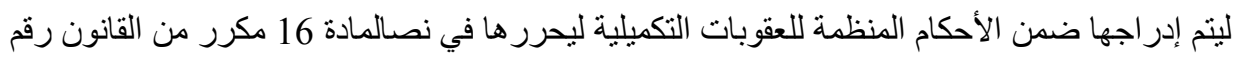

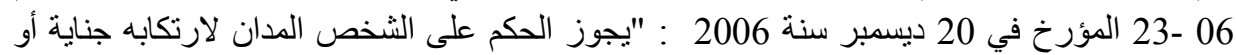

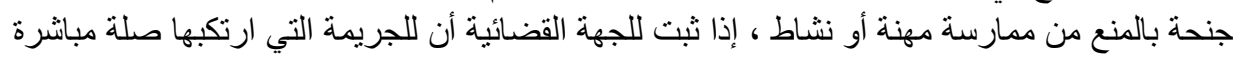

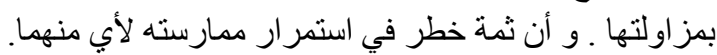

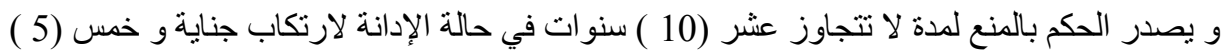

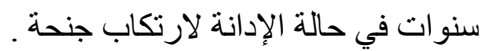
و يجوز أن يؤمر بالنفاذ المعجل بالنسبة لهذا الإجر اء."

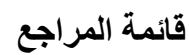
(1 1 1 1أحسن بوسقيعة، الوجيز في القانون الجزائي الخاص، الطبعة الرابعة عشر، الجزء الأول، دار هومة

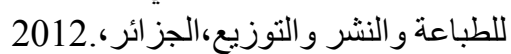

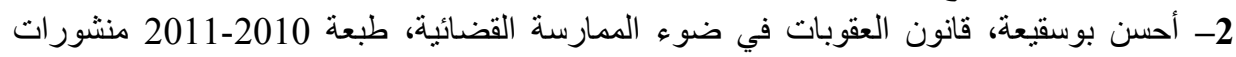

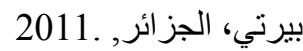
3-حسن ربيع،الإجهاض في نظر المشرع الجنائي (دراسةمقارنة)، الطبعة الرابعة، دار الثقافة

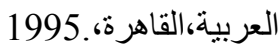
4-رؤوف عبيد، جرائم الاعتداء على الأشخاص والأموال، الطبعة الثامنة، دار الفكر

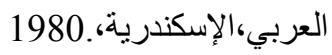

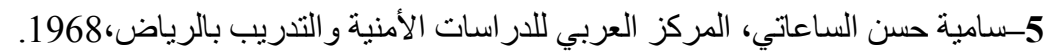
6-شريف سيد كامل، جرائم الاعتداء على الأشخاص، الطبعة الأولى، دار النهضة العباضية العربية، القاهرة 2004. 7-عبد المهيمن بكر ، جر ائمالاعتداء على الأشخاص والأموال، القسم الخاص في قانون العقوبات، دار

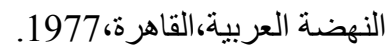
8_عبد الرحيم صدقي، جرائم الأسرة في الثريعة الإسلامية والقانون الصصريو الفرنسي، مكتبة نهضة

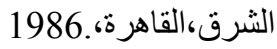
9-فتوح عبد الله الثناذلي، جرائم الاعتداء على الأثخاص والأموال، دار المطبوعات

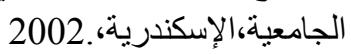




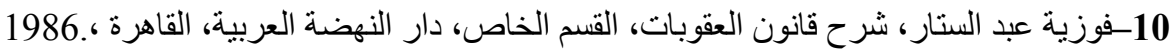

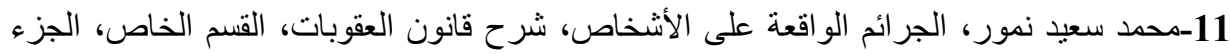

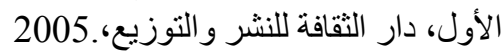

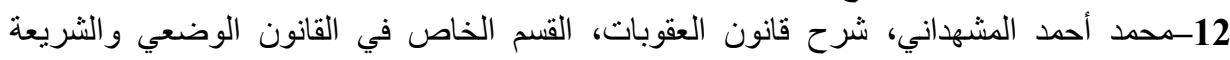

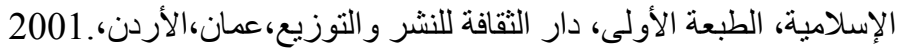

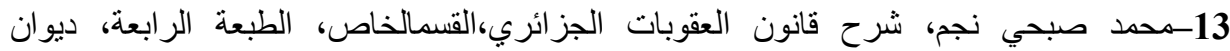

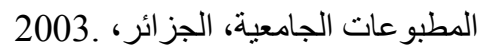

14-محمود نجيب حسني، شرح قانون العقوبات، القسم الخاص، الطبعة الرابعة، دار النهضة

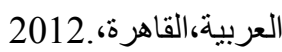
15-مليكة ثابت بن عزة، جريمة الإجهاض بين الثريعة الإسلامية والتشريع الجنائي الجزائري، دار

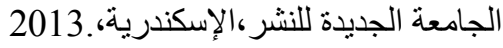
2) - الرسائل العلمية 1 1-منال مروان منجد، الإجهاض في القانة القانون الجنائي، (دراسة مقارنة)، رسالة لنيل درجة الدكتور اه،

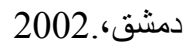
2-عماد الدين وادي، إجر ام المرأة ودور المؤسسات العقابية في إعادة إدماجها، رسالة دكتور اه، جامعة

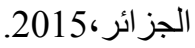

